\title{
Difference between early clinical features of swine origin A H1N1 influenza confirmed and not confirmed infection in Mexico
}

\author{
Mónica Rodríguez-Valero ${ }^{1}$, Héctor Manuel Prado Calleros ${ }^{1}$, Gerardo Arturo Bravo Escobar ${ }^{1}$, \\ Rafael Ricardo Valdez Vázquez ${ }^{2}$, Rafael Figueroa Moreno ${ }^{3}$, Guillermo Martínez Montes ${ }^{1}$, Simón \\ Kawa Karasik ${ }^{4}$ \\ ${ }^{1}$ Otorhinolaryngology Division, Hospital General Dr Manuel Gea Gonzalez, Mexico City, Mexico \\ ${ }^{2}$ Epidemiology Subdirector, Hospital General Dr Manuel Gea Gonzalez, Mexico City, Mexico \\ ${ }^{3}$ Clinical Epidemiology and Preventive Medicine Division, Hospital General Dr Manuel Gea Gonzalez, Mexico City, \\ Mexico \\ ${ }^{4}$ Executive Director, National Bioethics Commission, Mexico City, Mexico
}

\begin{abstract}
Introduction: The Swine Origin A H1N1 Influenza Virus (SOIV) pandemic emerged in April 2009 affecting people and health-care systems worldwide. This study examined the differences among the early clinical features presented in confirmed SOIV cases, those who tested negative for SOIV infection, fatalities, and hospitalized cases.

Methodology: We reviewed 1,024 initial medical records of patients presenting with acute respiratory symptoms who attended the respiratory emergency room of a general hospital in Mexico and had a confirmatory test for influenza AH1N1 by RT-PCR from April to December 2009.

Results: Out of 1,024 cases, 457 (44\%) were men with a mean age of $31 \pm 17$ years; however, of these, SOIV confirmed cases were younger $(26 \pm 8, \mathrm{p}=0.000)$. SOIV infection was confirmed in $36 \%$ of the patients. Most $(\%$ ?) cases presented mild infection, $20 \%$ of the patients required hospitalization, and $0.09 \%$ patients died. Asthma was more frequent in confirmed cases $(p=0.028)$. Presence of COPD, systemic arterial hypertension, and diabetes mellitus was significant in confirmed hospitalized cases. Pulmonary rales, wheezing, and sudden symptom onset were more frequent and statistically significant in confirmed patients. Influenza-like illness was more frequent in confirmed cases $(p=0.049)$.

Conclusions: This study presents one of the largest series of the new SOIV infection confirmed by RT-PCR reported. This infection is frequently mild and affects mainly young adults. Sudden symptoms onset, pulmonary rales, and wheezing are early features of this infection. Asthma, COPD, systemic arterial hypertension, and diabetes mellitus should be identified to identify potentially severe and fatal cases. ILI helps distinguish SOIV infection.
\end{abstract}

Key words: Swine Origin Influenza Virus A H1N1; influenza; flu; Influenza A H1N1; influenza A/Mexico/2009 (H1N1)

J Infect Dev Ctries 2012; 6(4):302-310.

(Received 21 September 2010 - Accepted 04 August 2011)

Copyright (C) 2012 Rodriguez-Valero et al. This is an open-access article distributed under the Creative Commons Attribution License, which permits unrestricted use, distribution, and reproduction in any medium, provided the original work is properly cited

\section{Introduction}

The known historical roots of the influenza A H1N1 virus can be traced to 1918 , when a virus currently thought to be of avian origin overcame the complex species barriers required to infect humans [1]. The SOIV is a triple-reassortant influenza virus containing genes from human, swine, and avian influenza viruses [4-7].

In April of 2009 the start of an epidemic caused by the Swine Origin A H1N1 Influenza Virus (SOIV) pandemic was described, initially referred to as Mexican flu. Since then, the world has suffered great consequences of this virus with an estimated 50 to
100 million deaths, more than any other influenza pandemic in history $[1,2,3]$. The first cases of this pandemic infection were identified in Mexico [7] and the United States [7-9]; the virus then spread rapidly to other regions of the world [7,10,11]. The World Health Organization (WHO) declared a pandemic phase 5 and 6, defined as human-to-human transmission of an animal or human-animal influenza reassortant virus able to cause sustained community level outbreaks in two or more countries in one WHO region and, in addition to the previous criteria, the involvement of two or more countries in another WHO region [12]. At the end of 2010, the WHO 
declared the beginning of the post-pandemic period [13].

Analyses have suggested that clinical manifestations of A/Mexico/2009 H1N1 influenza and seasonal influenza are similar, and may vary from asymptomatic to severe respiratory failure $[2,14,15]$. Initial clinical presentations of outpatient clinic cases and hospitalized patients have been barely reported.

Influenza-like illness (ILI) is defined by the Center for Disease Control (CDC) as fever (temperature $\geq 100^{\circ} \mathrm{F}$ or $37.8^{\circ} \mathrm{C}$ ) and either the presence of cough or sore throat in the absence of any known cause [16]. A confirmed case of 2009 H1N1 infection is defined by the $\mathrm{CDC}$ as the presence of ILI and a positive test result for the $2009 \mathrm{H} 1 \mathrm{~N} 1$ virus by either real-time reverse transcriptase polymerase chain reaction (RT-PCR) or viral culture. A probable case is defined by an ILI and a positive influenza A test result but negative results for seasonal $\mathrm{H} 1$ and $\mathrm{H} 3$ by RT-PCR. A suspected case does not meet either of the previous definitions but is considered in a person younger than 65 years hospitalized for ILI, or a person of any age with ILI and an epidemiological link to a confirmed or probable case within 7 days of illness onset $[2,16]$.

During the peak of a major outbreak of influenza, most cases of ILI are expected to be caused by the circulating virus. ILI is an important diagnostic clue for detecting and treating possible cases of a respiratory epidemic once the etiologic agent has been established, obviating the need of a confirmatory test in every case because, regardless of cause, most cases of ILI are mild and self-limiting, except in cases of high-risk groups, such as the extreme ages. The presence of ILI is very common; in some countries each adult and child presents an average of one to three and three to six episodes respectively per year of ILI [17]. Influenza A and influenza $B$ viruses have been described as the dominant viral agents of ILI, together accounting for only $35 \%$ of all cases. Other viruses have been identified as well; parainfluenza viruses, adenoviruses, respiratory syncytial virus (RSV), and enteroviruses account for nearly $9 \%$ of ILI cases [18]. The study of this syndrome and detection of circulating SOIV cases may be useful for selecting components of the seasonal vaccine and for describing disease incidence and burden.

Described high-risk factors for SOIV infection are an age older than 60 years or younger than 2 years, cardiac pathologies (except systemic arterial hypertension), diabetes mellitus, cancer, immunosupression, renal disease, pregnancy, difficult access to health services, and patients who attend for a second evaluation due to persistence or intensification of symptoms [13].

The world is now in the post-pandemic period. It is expected that the SOIV infection will continue to circulate as a seasonal virus for some years to come [13]. Knowledge of the characterization of initial clinical manifestations is important because it will help to distinguish patients with high probability of confirmed infection and severe cases in the first medical contact; therefore, the analysis of the data collected during this pandemic in the country where it started is of great value and will help as long as this viral strain continues to circulate.

The aim of this study is to determine if there is any difference between the early clinical features presented in confirmed SOIV cases and in those patients who tested negative for the viral strain, between fatal and no fatal cases, and to identify the risk conditions to develop a severe or fatal disease.

\section{Methodology}

We reviewed 1,364 initial medical records of patients presenting acute respiratory symptoms and who underwent a nasopharyngeal swab analyzed for the presence of SOIV with the use of real time protein chain reaction (RT-PCR) as a confirmatory test. All patients attended the respiratory emergency room of the General Hospital Dr Manuel Gea Gonzalez in Mexico City, Mexico, from April to December 2009. A total of 1,073 medical records were included and 291 records were excluded because they presented incomplete demographic and clinical data.

Nasopharyngeal swabs taken during the initial evaluation were put into a viral transport media tube and sent to the laboratory at the Instituto Nacional de Nutrición y Ciencias Médicas Salvador Zubirán, Mexico City, where they were tested by rRT-PCR using standardized $\mathrm{CDC}$ protocols for influenza A and B [19]. Subtyping for influenza A to detect 2009 H1N1 was conducted using a standardized CDC protocol [19]. DNA extraction was done automatically by the system NucliSENS easyMAG (bioMerieux, Boxtel, Netherlands). The Applied Biosystems Real Time PCR 7500 (Foster City, CA, USA) was used for the positive/negative assay to determine if a specific sequence was present (positive) or absent (negative) in the sample (Kit Invitrogen SuperScript ${ }^{\mathrm{TM}}$ III Platinum, Carlsbad, CA, 
USA). Primers sequence sets used were InfA, sw InfA and sw H1 [19]. The study was approved by the research ethics board.

\section{Statistical analysis}

Continuous variables were summarized as means ( $\pm \mathrm{SD}$ ) or medians (with interquartile ranges). For categorical variables the percentages of patients in each category were calculated. Clinical characteristics including systemic arterial hypertension, diabetes mellitus, asthma, cardiac disease, chronic obstructive pulmonary disease, cancer, HIV, rheumatic diseases, fever, sudden symptom onset (presentation of more than 3 symptoms or signs in less than 2 days), ILI, headache, myalgias, atralgias, cough, rhinorrhea, cervical lymphadenopaties, dyspnea, cianosis, diarrhea, pulmonary rales, pulmonary wheezing, sore throat, and altered consciousness were compared between subgroups of patients with the use of an unpaired Student's t-test, chi-square test, or Fisher's exact test, as appropriate. Patient subgroups were categorized as follows: without confirmed diagnosis, ILI, hospitalized, and deceased.

A $p$ value of less than 0.05 was considered statistically significant. All analyses were performed with the use of SPSS program version 17 (SPSS IBM, Chicago, USA).

\section{Results}

This study reports cases from the first eight months of the pandemic which comprised $53 \%$ of the pandemic duration. During this period confirmatory tests were performed on the majority of the patients. We present the clinical features found in patients with acute respiratory symptoms during the pandemic, who were tested in one occasion.

We evaluated medical charts from 567 women (55\%) and 457 men (44\%), which included twelve pregnant women (3\% of women in childbearing age, considered from 14 to 45 years old). The mean age was $31 \pm 17$ years. A statistical difference was found between SOIV RT-PCR confirmed infection and not confirmed cases $(p=0.000)$ : specifically confirmed patients were younger than the negative cases $(26 \pm 8$ and $30 \pm 7$ respectively).

In $36 \%$ of the patients SOIV infection was confirmed with RT-PCR, and 642 patients $(63 \%)$ had a negative test. Demographic characteristics are presented in Table 1. Almost half (47\%) of the patients evaluated were between 25 and 49 years old, and $21 \%$ of the confirmed cases were younger than
18 years old. Median days from the onset of symptoms to medical evaluation were the same fpr both SOIV confirmed cases and those who tested negative (two days). Fatal and hospitalized patients were almost equally presented in both groups mentioned previously $(1 \%, 26 \%$ and $1 \%, 21 \%$ respectively).

Forty-two percent of the evaluated population initiated symptoms 24 hours before the medical interview. Mild disease of the SOIV infection was the most frequent presentation form (78\%) but as many as $26 \%$ of the confirmed cases were hospitalized because of the presence of severe or complicated infection. On the other hand, the confirmatory test was positive in $40 \%$ of the hospitalized patients. Eleven patients died (1\% of the studied population), and SOIV infection was confirmed in 4 of them $(33 \%)$.

Chronic concomitant diseases are shown in Table 2. In comparison between confirmed cases and negative RT-PCR patients, asthma was the only condition that had a statistically significant difference $(p=0.028)$. Systemic arterial hypertension, COPD, and diabetes mellitus were also statistically significantly different in the hospitalized and outpatient groups ( $p=0.012, p=0.001, p<0.001)$.

In the aim of distinguishing confirmed cases from suspected patients, symptoms between positive and negative SIOV RT-PCR groups were compared. A sudden onset of symptoms (less than two days), presence of pulmonary rales, and wheezing presented a statistically significant difference: all were more frequent in SOIV-infected patients $(p=0.05,0.052$, 0.21 , respectively) than in non-SOIV patients. Rhinorrhea was more frequent in ambulatory patients than in hospitalized and fatal cases $(p=0.009)$. The findings of pulmonary rales and wheezing as well as a respiratory rate above 20 per minute were more frequent in hospitalized and fatal cases than they were in other cases, with a statistically significant difference ( $p=0.052$ and $p=0.021)$ (Table 3 ).

ILI, which was found in almost half of the population $(48 \%)$, was helpful differentiating confirmed cases from RT-PCR negative cases ( $p=$ 0.049 ), though it was not useful in identifying hospitalized or fatal cases. The predictive positive value was $52 \%$, specificity was $33 \%$, and sensibility was $17 \%$ in the clinical scenario of the first contact.

On the other hand, fever, headache, sudden onset of symptoms, and rhinorrea were symptoms more 
Table 1. Demographic characteristics of patients presenting acute respiratory symptoms

\begin{tabular}{|l|c|c|c|c|}
\hline CHARACTERISTIC & TOTAL & $\begin{array}{l}\text { SOIV } \\
\text { CONFIRMED } \\
\text { CASES }\end{array}$ & $\begin{array}{l}\text { RT-PCR } \\
\text { NEGATIVE } \\
\text { CASES }\end{array}$ & $\begin{array}{l}\text { OTHER } \\
\text { INFLUENZA }\end{array}$ \\
\hline Patients & $1364 *$ & 462 & 840 & 62 \\
\hline Mean age (years) & $31 \pm 18$ & $24 \pm 16$ & $34 \pm 17$ & $33 \pm 13$ \\
\hline $\begin{array}{l}\text { Women } \\
\text { Men }\end{array}$ & $\begin{array}{l}623(45 \%) \\
741(54 \%)\end{array}$ & $\begin{array}{l}240(51 \%) \\
222(48 \%)\end{array}$ & $\begin{array}{l}473(56 \%) \\
367(43 \%)\end{array}$ & $\begin{array}{l}28(45 \%) \\
34(54 \%)\end{array}$ \\
\hline Hospitalized cases & $313(22 \%)$ & $112(24 \%)$ & $185(22 \%)$ & $16(25 \%)$ \\
\hline Fatal cases & $11(0.8 \%)$ & $4(0.8 \%)$ & $7(0.8 \%)$ & 0 \\
\hline Pregnant women & 13 & 4 & 8 & 1 \\
\hline
\end{tabular}

SOIV: Swine Origin Influenza Virus, RT-PCR: real time polymerase chain reaction, ILI: influenza like illness

* We reviewed 1,364 medicals charts of patients presenting acute respiratory symptoms; 299 medical charts were incomplete.

Table 2. Concomitant diseases of patients presenting acute respiratory symptoms

\begin{tabular}{|c|c|c|c|c|c|}
\hline COMORBIDITIES & $\begin{array}{r}\text { TOTAL } \\
(n=1065)\end{array}$ & $\begin{array}{c}\text { SOIV } \\
\text { CONFIRMED } \\
\text { CASES } \\
(n=373) \\
\end{array}$ & $\begin{array}{c}\text { RT-PCR } \\
\text { NEGATIVE } \\
\text { CASES } \\
(n=642) \\
\end{array}$ & $\begin{array}{c}\text { HOSPITALIZED } \\
\text { PATIENTS } \\
(n=259)\end{array}$ & $\begin{array}{c}\text { FATAL CASES } \\
\qquad(n=11)\end{array}$ \\
\hline $\begin{array}{l}\text { Systemic arterial } \\
\text { hypertension }\end{array}$ & $91(8 \%)$ & $20(5 \%)$ & $63(9 \%)$ & $40(15 \%)$ & $1(9 \%)$ \\
\hline Diabetes Mellitus & $73(6 \%)$ & $23(6 \%)$ & $44(6 \%)$ & $31(11 \%)$ & $2(18 \%)$ \\
\hline Asthma & $44(4 \%)$ & $24(6 \%)$ & $18(2 \%)$ & $14(5 \%)$ & 0 \\
\hline Cardiac disease & $34(3 \%)$ & $12(3 \%)$ & $20(3 \%)$ & $9(3 \%)$ & 0 \\
\hline COPD & $22(2 \%)$ & $6(1 \%)$ & $14(2 \%)$ & $12(4 \%)$ & 0 \\
\hline Cancer & $14(1 \%)$ & $3(0.8 \%)$ & $11(1 \%)$ & $6(2 \%)$ & 0 \\
\hline HIV & $3(0.4 \%)$ & $2(0.5 \%)$ & $2(0.3 \%)$ & $1(0.3 \%)$ & 0 \\
\hline Rheumatic diseases & $8(0.7 \%)$ & $2(0.5 \%)$ & $6(0.9 \%)$ & $2(0.7 \%)$ & 0 \\
\hline
\end{tabular}


Table 3. Early clinical features of patients presenting acute respiratory symptoms

\begin{tabular}{|l|c|c|c|c|c|c|}
\hline \multicolumn{1}{|c|}{$\begin{array}{c}\text { CLINICAL } \\
\text { FEATURE }\end{array}$} & $\begin{array}{c}\text { TOTAL } \\
(\mathbf{n}=\mathbf{1 0 6 5})\end{array}$ & $\begin{array}{c}\text { SOIV } \\
\text { CNFIRMED } \\
\text { CASES } \\
(\mathbf{n}=\mathbf{3 7 3})\end{array}$ & $\begin{array}{c}\text { NEGATIVE } \\
\text { CASES } \\
(\mathbf{n = 6 4 2})\end{array}$ & $\boldsymbol{p}^{*}$ & $\begin{array}{c}\text { HOSPITALIZED } \\
\text { PATIENTS } \\
(\mathbf{n = 2 5 9 )}\end{array}$ & $\begin{array}{c}\text { FATAL } \\
\text { CASES } \\
(\mathbf{n}=\mathbf{1 1})\end{array}$ \\
\hline Fever & $629(59 \%)$ & $222(59 \%)$ & $373(58 \%)$ & NS & $163(62 \%)$ & $4(36 \%)$ \\
\hline $\begin{array}{l}\text { Sudden symptoms } \\
\text { onset }\end{array}$ & $706(66 \%)$ & $280(75 \%)$ & $426(66 \%)$ & .001 & $170(65 \%)$ & $1(9 \%)$ \\
\hline ILI & $528(49 \%)$ & $195(52 \%)$ & $303(47 \%)$ & .052 & $144(55 \%)$ & $3(27 \%)$ \\
\hline Headache & $514(48 \%)$ & $178(47 \%)$ & $312(48 \%)$ & NS & $121(46 \%)$ & $2(18 \%)$ \\
\hline $\begin{array}{l}\text { Myalgias and } \\
\text { arthralgias }\end{array}$ & $541(42 \%)$ & $158(42 \%)$ & $274(42 \%)$ & NS & $100(38 \%)$ & $1(9 \%)$ \\
\hline Cough & $683(64 \%)$ & $242(64 \%)$ & $412(64 \%)$ & NS & $182(70 \%)$ & $4(36 \%)$ \\
\hline Rhinorrhea & $631(60 \%)$ & $228(61 \%)$ & $384(59 \%)$ & NS & $151(58 \%)$ & $4(36 \%)$ \\
\hline $\begin{array}{l}\text { Cervical } \\
\text { lymphadenopaties }\end{array}$ & $109(10 \%)$ & $30(8 \%)$ & $73(11 \%)$ & NS & $26(10 \%)$ & $2(18 \%)$ \\
\hline Dyspnea & $171(16 \%)$ & $59(15 \%)$ & $104(16 \%)$ & NS & $65(25 \%)$ & $2(18 \%)$ \\
\hline Cianosis & $8(0.09 \%)$ & $5(1 \%)$ & $3(0.4 \%)$ & NS & $4(1 \%)$ & 0 \\
\hline Diarrhea & $70(6 \%)$ & $27(7 \%)$ & $39(6 \%)$ & NS & $22(8 \%)$ & 0 \\
\hline Pulmonary rales & $54(5 \%)$ & $31(8 \%)$ & $19(2 \%)$ & .000 & $36(13 \%)$ & $1(9 \%)$ \\
\hline Pulmonary wheezing & $33(3 \%)$ & $16(4 \%)$ & $13(2 \%)$ & .011 & $19(7 \%)$ & $3(27 \%)$ \\
\hline Sore throat & $403(37 \%)$ & $144(38 \%)$ & $234(36 \%)$ & NS & $95(36 \%)$ & $2(18 \%)$ \\
\hline
\end{tabular}

SOIV: Swine Origin Influenza Virus, RT-PCR: real time polymerase chain reaction, ILI: influenza like illness, NS: not significant

${ }^{*}$ Correlation between confirmed SOIV cases and negative RT-PCR cases

frequently observed in mild cases of confirmed A H1N1 influenza. Non-productive cough in patients with acute respiratory symptoms was more common than productive cough.

Sudden onset of symptoms reported by the patients was the only clinical characteristic that helped distinguish mild SOIV confirmed infection from those patients who tested SOIV RT-PCR negative $(p=0.002)$.

Fever was more commonly presented by fatal confirmed cases than in those not confirmed. Interestingly, symptoms were more frequently observed in survival patients than in fatal cases, but clinical findings such as pulmonary wheezing and cervical lymphadenopaties were presented more commonly by the deceased subgroup. A sudden onset of symptoms was only manifested by one fatal case.

\section{Discussion}

A novel virus of swine origin emerged among people in our country during the spring of 2009 and spread with travellers worldwide, resulting in the first influenza pandemic since 1968. By October 2009, confirmed human cases of pandemic SOIV were reported in 195 countries. While the majority of illnesses caused by pandemic SOIV infection have been self-limited, mild-to-moderate uncomplicated diseases, severe complications including fatal outcomes have been reported. With regard to the incidence of the disease severity, our results are similar to those reported previously [20]. This study presents one of the largest series of the new SOIV infection confirmed by RT-PCR.

Although other investigations have suggested that SOIV disproportionately affects the pediatric population, we report a high incidence in young adults, especially those between 25 and 49 years of 
age. The incidence of pandemic influenza in children was not as high in our study as that reported in other investigations [4].

The results we obtained confirm data previously published by the Centers for Disease Control and Prevention (CDC), which states that this infection mainly affects young patients, that the number of hospitalized cases is greater than the number of deaths, and that a fatal outcome usually occurs in people younger than 64 years [21]. Seventy-seven percent of cases reported in Mexico were between 18 and 64 years old, and we found similar ranges in our study population. These observations may be a result of the similarities among previous influenza virus infections, epidemic effect, the social response to the epidemic, or because of the age distribution in our population.

Seasonal influenza associated hospitalization rates increase dramatically with age [22]. Another difference with seasonal influenza is that $90 \%$ of the deaths correspond to patients older than 65 years [23]. In our study we found that $20 \%$ of SOIV confirmed cases required hospitalization (mean age of $29 \pm 9$ years) with a mortality of $1 \%$. As previously mentioned, the affected population in this new epidemic is younger than the one observed in seasonal influenza [22,23].

In contrast to the traditional risk factors mentioned in the beginning of the paper, we found that the presence of diabetes mellitus, COPD, and systemic arterial hypertension may predispose to the development of severe cases because these conditions were more frequent in hospitalized confirmed patients. Although systemic arterial hypertension had not been considered as a risk factor, we suggest that special attention should be paid while evaluating patients who suffer this disease because they were more frequently hospitalized.

In the previous studies shown in Table 4 the association with diabetes mellitus disease has been reported. Probably patients who suffer diabetes mellitus have an altered immunological response and decreased response to infections, causing mayor systemic compromise and a worse antiviral response. Contrary to the results shown in other studies [20], our results show that immunosuppression, whether due to primary immunosuppressive conditions such as HIV infection or secondary conditions such as malignancy or rheumatic disease, did not correlate with SOIV confirmed infection.

Fever was a more common symptom in our population in comparison to the other confirmed cases of Bin Cao et al. [7], while in the other studies, which present probable and confirmed cases, it was much higher. Diarrhoea is more frequently presented in young individuals; the Novel Swine-Origin Influenza A H1N1 Virus Investigation Team also noted this in their work [4].

The only clinical features that helped differentiate confirmed cases were a sudden onset, pulmonary rales, and wheezing. This observation supports the idea that SOIV infection is a mild disease and presents as a common upper respiratory infection, with the exception that patients describe rapid symptom onset. The presence of pulmonary rales and wheezing also distinguishes SOIV infection.

Based on the presented data (hospitalized and fatal cases) which show slight differences between confirmed SOIV infection and RT-PCR negative cases, we consider that the tendency to not perform a confirmation test in every case of suspected infection by A H1N1 influenza during the intrapandemic period was adequate, especially if the patient lived in affected areas or presented with mild disease $[21,25]$.

Even though ILI and nasopharyngeal swab have been reported to be useful for the SOIV detection $[2,16]$, in our experience they did not help differentiate confirmed from unconfirmed cases, and they did not facilitate distinction from ambulatory and hospitalized patients. The median time from the onset of the first symptoms of illness to the first positive real-time RT-PCR test result for the virus is one day (range, 0 to 2) [7]. We assume that the nasopharyngeal swabs were not useful, as expected, because of errors in the sampling technique and the fact that a swab sample was taken on just one occasion, so the affected population may be underestimated. On the other hand, ILI cases may be attributed to upper respiratory tract infections of different etiologies that were not evaluated. When a pandemic subtype has been detected in a susceptible population, it is probable that influenza-like illness has a high positive predictive value. However, the low positive predictive value of ILI may have been negatively influenced by the alert response of the population; i.e., although many people who present acute respiratory symptoms usually do not seek medical attention, during this pandemic period they looked for medical evaluation in health services [26,27].

Cervical lymphadenopaties are present in $8 \%$ of the confirmed cases, and similar observations were made by Zambon et al. and Falsey et al. [26,27]. 
Table 4. Comparison of initial clinical features in fatal cases

\begin{tabular}{|l|c|c|c|c|}
\hline CHARACTERISTICS & Fatal cases & $\begin{array}{l}\text { Liam J Donaldson \& } \\
\text { cols. (29) }\end{array}$ & Louie \& cols. (5) & $\begin{array}{l}\text { Domínguez Cherit \& } \\
\text { cols. } \\
\text { ICU (30) }\end{array}$ \\
\hline Patients & 11 & & 110 & 58 \\
\hline Mean age (years) & 42 & & 46 & 44 \\
\hline Children & $9 \%$ & & & $3 \%$ \\
\hline Comorbidities & & & $16 \%$ & $3 \%$ \\
\hline Asthma & $0 \%$ & $3 \%$ & $25 \%$ & $25 \%$ \\
\hline Systemic arterial hypertension & $9 \%$ & $2 \%$ & $6 \%$ & \\
\hline Pregnant & 0 & $3 \%$ & $18 \%$ & 6 \\
\hline Diabetes Mellitus & $18 \%$ & $<1 \%$ & $81 \%$ & $17 \%$ \\
\hline Days (mean) & 7 & 3 & $83 \%$ & $100 \%$ \\
\hline Dyspnea & $18 \%$ & & $9 \%$ & \\
\hline Fever & $36 \%$ & & $33 \%$ & \\
\hline Rhinorrhea & $36 \%$ & & $86 \%$ & \\
\hline Myalgias & $9 \%$ & & $15 \%$ & \\
\hline Cough & $36 \%$ & & $25 \%$ & $57 \%$ \\
\hline Headache & $18 \%$ & & $12 \%$ & \\
\hline Sore throat & $18 \%$ & & $18 \%$ & \\
\hline Altered conciousness & $27 \%$ & & & $30 \%$ \\
\hline Diarrhea & $0 \%$ & & & \\
\hline
\end{tabular}

Table 5. Comparison of initial clinical features of patients with SOIV A H1N1 infection

\begin{tabular}{|l|l|l|l|l|l|}
\hline CHARACTERISTICS & $\begin{array}{l}\text { SOIV } \\
\text { Confirmed } \\
\text { cases }\end{array}$ & $\begin{array}{l}\text { Bin Cao \& } \\
\text { cols.(7) }\end{array}$ & $\begin{array}{l}\text { Novel Swine-Origin } \\
\text { Influenza A H1N1 } \\
\text { Virus Investigation } \\
\text { Team (4) }\end{array}$ & $\begin{array}{l}\text { Louie LK \& } \\
\text { cols. (24) }\end{array}$ & $\begin{array}{l}\text { Justin Lessler } \\
\text { \& cols. (28) }\end{array}$ \\
\hline Patients & $462 *$ & $426 *$ & 642 & 1088 & 115 \\
\hline Mean age (years) & 24 & 23 & 20 & 27 & 16 \\
\hline Children & $34 \%$ & $27 \%$ & $60 \%$ & $31 \%$ & $14-19$ years \\
\hline Studied population & Open & Open & Students & Hospitalized & Students \\
\hline Deaths & $0.8 \%$ & $0 \%$ & $6 \%$ & $10 \%$ & $0 \%$ \\
\hline Fever & $59 \%$ & $36 \%$ & $94 \%$ & $89 \%$ & $93 \%$ \\
\hline Cough & $64 \%$ & $69 \%$ & $92 \%$ & $66 \%$ & $90 \%$ \\
\hline Headache & $48 \%$ & $19 \%$ & & $19 \%$ & $79 \%$ \\
\hline Rhinorrhea & $60 \%$ & $23 \%$ & & $20 \%$ & $69 \%$ \\
\hline Myalgias and arthralgias & $42 \%$ & $10 \%$ & & $33 \%$ & $76 \%$ \\
\hline Dyspnea & $16 \%$ & $10 \%$ & & $56 \%$ & \\
\hline Sore Throat & $37 \%$ & $36 \%$ & $66 \%$ & $25 \%$ & $76 \%$ \\
\hline Diarrhea & $6 \%$ & $2.8 \%$ & $25 \%$ & $20 \%$ & $26 \%$ \\
\hline$*$ * & & & & \\
\hline
\end{tabular}


The clinical presentation of uncomplicated influenza A cases, independently of the subtype, is similar at any age. There are symptoms that vary in frequency according to the disease subtype; for an example, during Asiatic pandemic in 1957 (H2N2), the most frequent presenting symptoms were headache and sore throat. Other subtypes are associated with different presenting symptoms and severity. The H3N2 subtype presents with symptoms more severe than the human H1N1 subtype. The diversity of the clinical presentations of the epidemic influenza A infection is different from that of the interpandemic influenza [23,28]. The recent SOIV infection in our population frequently presented with sudden onset, cough, and rhinorrhea.

Table 5 shows a comparison between our results and the data observed in other published studies regarding the clinical presentation of this pandemic. Only the study published by Cao et al. [7] presents exclusively confirmed cases; the other three studies show data from confirmed and probable cases. Our studied population described more symptoms than the patients followed in the investigation by Cao et al., and mortality was slightly higher in our group. Socioeconomic status may contribute to these differences. With regard to symptoms, our results are similar to those described in a study by Louie et al. [24] in which only hospitalized patients were investigated, so as mentioned previously, socioeconomic status may have influenced this difference. It is important to notice that despite the low socioeconomic status of the patients, mortality remained low. Another study reported a $30 \%$ death rate in children [5] (Table 4). In our study, sudden onset of symptoms was manifested only in one fatal case. Mean days from onset of symptoms to medical evaluation were similar to those reported in the Mexican population, but different from those in studies of the British population [29,30].

Two weak areas in the data collection system make it the main limitation of the study; specifically, incomplete evaluation forms were found, and followup visits were not performed.

This study presents one of the largest series of the new Swine Origin Influenza Virus A H1N1 infection confirmed by RT-PCR. Our results show that this virus infection is frequently mild and affects a mainly young adult population. Sudden onset of symptoms, pulmonary rales, and wheezing are early features of severe confirmed Swine Origin Influenza Virus A H1N1 infection. Risk factors, such as asthma, COPD, systemic arterial hypertension, and diabetes mellitus, should be identified to prevent and treat potentially severe and fatal cases.

\section{References}

1. Zimmer SM and Burke DS (2009) Historical perspective emergence of influenza A (H1N1) viruses. N Engl J Med 361: 279-285.

2. Sullivan SJ, Jacobson RM, Dowdle WR, Poland GA (2010) 2009 H1N1 Influenza. Mayo Clin Proc 85: 64-76.

3. De Lamballerie X and Gould EA (2009) With reference to Mexican flu. Influenza and Other Respiratory Viruses 3: 203.

4. Novel Swine-Origin Influenza A (H1N1) Virus Investigation Team (2009) Emergence of a novel swineorigin influenza A (H1N1) virus in humans. N Engl J Med 360: 2605-2615.

5. Trifonov V, Khiabanian H, Greenbaum B, Rabadan R (2009) The origin of the recent swine influenza $A(H 1 N 1)$ virus infecting humans. Euro Surveill 14: pii 19193.

6. Centers for Disease Control and Prevention (2009) Update: drug susceptibility of swine origin influenza A (H1N1) viruses, April 2009. MMWR Morb Mortal Wkly Rep 58: 433-435.

7. Cao B, Li XW, Mao Y, Wang J, Lu HZ, Chen YS, Liang ZA, Liang L, Zhang SJ, Zhang B, Gu L, Lu LH, Wang DY, Wang C; National Influenza A Pandemic (H1N1) 2009 Clinical Investigation Group of China (2009) Clinical Features of the Initial Cases of 2009 Pandemic Influenza A (H1N1) Virus Infection in China. N Engl J Med 361: 25072517.

8. Centers for Disease Control and Prevention (2009) Swineorigin influenza A (H1N1) virus infections in a school: New York City, April 2009. MMWR Morb Mortal Wkly Rep 58: 470-472.

9. Centers for Disease Control and Prevention (2009) Swine influenza A (H1N1) infection in two children: Southern California, March-April 2009. MMWR Morb Mortal Wkly Rep 58: 400-402.

10. Centers for Disease Control and Prevention (2009) Update: infections with a swine-origin influenza A (H1N1) virus: United States and other countries, April 28, 2009. MMWR Morb Mortal Wkly Rep 58: 431-433.

11. Naffakh N and Van der Werf SV (2009) April 2009: an outbreak of swine-origin influenza $\mathrm{A}(\mathrm{H} 1 \mathrm{~N} 1)$ virus with evidence for human-to-human transmission. Microbes Infect 11: 725-728.

12. World Health Organization (2009) New influenza A (H1N1) virus: global epidemiological situation, June 2009. Wkly Epidemiol Rec 84: 249-257.

13. World Health Organization WHO recommendations for the post-pandemic period Pandemic (H1N1) 2009 briefing note 23: Director-General's opening statement at virtual press conference. Available at http://www.who.org. 10 August 2010

14. Komiya N, Gu Y, Kamiya H, Yahata Y, Matsui T, Yasui Y, Okabe N (2009) Clinical features of cases of influenza A (H1N1)v in Osaka prefecture, Japan, May 2009. Euro Surveill 14: pii 19272.

15. Belgian Working Group on Influenza A(H1N1)v (2009) Influenza A(H1N1)v virus infections in Belgium, May-June 2009. Euro Surveill 14.

16. Centers for Disease Control and Prevention (CDC) Interim guidance on case definitions to be used for investigations of 
novel influenza A $\quad(\mathrm{H} 1 \mathrm{~N} 1) \quad$ cases. http://www.dphss.guam.gov/docs/swine_flu/H1N1. 10 November 2009.

17. Centers for Disease Control and Prevention (2001) Considerations for distinguishing influenza-like illness from inhalational anthrax. MMWR Morb Mortal Wkly Rep 50: 984-986.

18. Forshey BM, Laguna-Tores VA, Vilcarromero S, Bazan I, Rocha C, Morrison AC, Stoddard ST, Alegre Y, Gomez J, Scott TW, Kochel TJ (2010) Epidemiology of influenza-like illness in the Amazon Basin of Peru, 2008-2009. Influenza and Other Respiratory Viruses 4: 235-243.

19. World Health Organization (2009) http://www.who.int/csr/resources/publications/swineflu/CD CrealtimeRTPCRprotocol 20090428.pdfReal Time PCR protocol. Last accessed on 3 April 2012.

20. World Health Organization (2009) Clinical management of human infection with pandemic (H1N1) 2009: revised guidance. Available at http://www.who.int/csr/resources/publications/swineflu/clini cal management h1n1.pdfNovember 2009

21. Centers for Disease Control and Prevention (2009) CDC Estimates of 2009 H1N1 Influenza Cases, Hospitalizations and Deaths in the United States. April-October 17, 2009. Available at http://www.cdc.gov/h1n1flu/estimates/April_October_17.ht m. Last accessed on 3 April 2012.

22. Thompson WW, Shay DK, Weintraub E, Brammer L, Bridges CB, Cox NJ, Fukuda K (2004) Influenza-Associated Hospitalizations in the United States. JAMA 292: 13331340.

23. British Infection Society British Thoracic Society Health Protection Agency (2006) Pandemic Influenza - Clinical Guidelines - Updated 29 March 2006: Clinical management of patients with an influenza-like illness during an influenza pandemic. Version 10.5 Provisional guidelines from the British Infection Society British Thoracic Society Health Protection Agency.

24. Louie JK, Acosta M, Winter K, Jean C, Gavali S, Schechter R, Vugia D, Harriman K, Matyas B, Glaser CA, Samuel MC, Rosenberg J, Talarico J, Hatch D; California Pandemic (H1N1) Working Group: Aranki F, Bancroft E, Barney C, Batson P, Botta J, Byron-Cooper O, Chapman R, Cheung M, Cody S, Deckert A, Falade E, Farley S, Fortino S, Foster L,
Ginsberg M, Gregory B, Hammond L, Henn J, Hernandez LB, Johnson R, Jonah C, Kempf J, Kriner P, Lindsay A, MacLean M, Nelson F, Norman A, Ohikhuare M, Pan E, Rose K, Ryals R, Salce E, Sallenave CS, Schwartz F, Shah N, Starr M, Tait KM, Tighe BE, Trotter M, Wada T, Walker JA, Boston E, Nevarez M, Larsen J, Salibay C, Messenger S, Schnurr D (2009) Factors Associated with Death or Hospitalization Due to Pandemic 209 Influenza A(H1N1) Infection in California. JAMA 302: 1896-1902

25. Influenza Situación Actual de la Epidemia. Available at www.salud.gob.mx. 20 November 2009.

26. Zambon MC, Stockton JD, Clewley JP, Fleming DM (2001) Contribution of influenza and respiratory syncytial virus to community cases of influenza-like illness: an observational study. Lancet 358: 1410-1416.

27. Falsey AR, Treanor JJ, Betts RF, Walsh EE (1992) Viral respiratory infections in the institutionalized elderly: clinical and epidemiologic findings. J Am Geriatr Soc 40: 115-19.

28. Simonsen L, Clarke MJ, Williamson GD, Stroup DF, Arden NH, Schonberger LB (1997) The impact of influenza epidemics on mortality: introducing a severity index. Am J Public Health 87: 1944-1950.

29. Domínguez-Cherit G, Lapinsky SE, Macias AE, Pinto R, Espinosa-Perez L, de la Torre A, Poblano-Morales M, Baltazar-Torres JA, Bautista E, Martinez A, Martinez MA, Rivero E, Valdez R, Ruiz-Palacios G, Hernández M, Stewart TE, Fowler RA (2009) Critically Ill Patients With Influenza A(H1N1) in Mexico. JAMA 302: 1880-1887

30. Donaldson LJ, Rutter PD, Ellis BM, Greaves FE, Mytton OT, Pebody RG, Yardley IE (2009) Mortality from pandemic A/H1N1 2009 influenza in England: public health surveillance study. BMJ 339: b5213.

\section{Corresponding author}

Mónica Rodríguez-Valero

Hospital General Dr Manuel Gea Gonzalez

Calzada de Tlalpan 4800

Colonia Sección XVI Delegación Tlalpan

Distrito Federal, México 14080

Telephone: 015540003000 , extension 3047

Email:monirodval@yahoo.com

Conflict of interests: No conflict of interests is declared. 